\title{
Do individual characteristics influence the Beta-elliptic modeling errors during ellipse drawing movements?
}

Thameur Dhieb ${ }^{\mathrm{a}, \mathrm{b}}$, Nasser Rezzoug ${ }^{\mathrm{c}, \mathrm{d},{ }^{*}, \text { Houcine Boubaker }}{ }^{\mathrm{b}}$, Mounir Ben Ayed $^{\mathrm{b}, \mathrm{e}}$ and Adel M. Alimi ${ }^{\mathrm{b}, \mathrm{f}}$

${ }^{a}$ University of Sousse, ISITCom, 4011, Sousse, Tunisia

${ }^{b}$ REGIM-Lab.: REsearch Groups in Intelligent Machines, University of Sfax, ENIS, BP 1173, Sfax, 3038, Tunisia

${ }^{c}$ Inria, Centre Bordeaux Sud-Ouest, Equipe Projet AUCTUS Inria /IMS (Univ.

Bordeaux, CNRS UMR5218), F-33405 Talence, France

${ }^{d}$ Université de Toulon, CS 60584 - 83041 Toulon Cedex 9, France

${ }^{e}$ Computer Sciences and Communication Department, Faculty of Sciences of Sfax, University of Sfax, Sfax, Tunisia.

${ }^{f}$ Department of Electrical and Electronic Engineering Science, Faculty of Engineering and the Built Environment, University of Johannesburg, South Africa.

Thameur Dhieb (thameur.dhieb@regim.usf.tn)

Nasser Rezzoug (* Corresponding author) (rezzoug@univ-tln.fr)

Houcine Boubaker (houcine.boubaker@regim.usf.tn)

Mounir Ben Ayed (mounir.benayed@regim.usf.tn)

Adel M Alimi (adel.alimi@regim.usf.tn) 


\title{
Do individual characteristics influence the Beta-elliptic modeling errors during ellipse drawing movements?
}

\begin{abstract}
This paper investigates whether age, gender, and degree of familiarity with writing have an influence on the Beta-elliptic model errors during hand-drawing on a graphical tablet. A database of elliptical hand drawing movements was built within a sample of 99 participants aged between 19 and 85 years. Using the Betaelliptic model, the velocity profile was modeled by overlapped Beta functions and the drawing trajectory was segmented between velocity extrema and each segment geometry was modeled by elliptic arcs. Average absolute and relative geometric, curvature and curvilinear velocity errors were $0.27 \mathrm{~mm}, 0.68 \%, 4.54$ $\mathrm{mm}, 0.48 \%, 4.68 \mathrm{~mm} / \mathrm{s}$, and $8.79 \%$ respectively. Statistical analyses revealed not significant or low correlation between modeling errors and age and movement velocity, and no significant or low error differences according to gender or degree of familiarity with writing.
\end{abstract}

\section{KEYWORDS}

Beta-elliptic model; handwriting; aging; modeling errors.

\section{Introduction}

As gait and balance, drawing and handwriting are complex skills involving several sensory-motor processes. With aging, there is a natural decline of cognitive and sensorimotor functions affecting fine motor control (Seidler et al. 2010). Drawing and handwriting are no exception and are also affected by this decline (Caligiuri et al. 2014; Dhieb, Rezzoug, et al. 2019). Nowadays, graphical tablets associated with appropriate signal processing allow an objective analysis of writing and drawing, 1) for documenting the effect of aging and highlighting the neural, motor and sensory effects, 2) to develop new clinical tests for neurodegenerative disease early detection (De Stefano et al. 2019), and 3) for more engineering-oriented applications such as signature automatic recognition (Caligiuri et al. 2014; Parziale et al. 2019) or authentication for 
forensics (Kumar et al. 2014; Dhieb et al. 2020). Writing is also influenced by other individual characteristics such as gender (Liwicki et al. 2007) e.g.

Modifications of writing characteristics have been observed due to aging: a decrease in writing speed (Dixon et al. 1993; Rodríguez-Aranda 2003; Rosenblum and Werner 2006; Burger and McCluskey 2011; Caligiuri et al. 2014), lower pen pressure (Rosenblum and Werner 2006; Caligiuri et al. 2014), more time in the air (Rosenblum and Werner 2006), a decrease of mean velocity/maximum velocity and the increase of correlation between velocities in the $\mathrm{X}$ and $\mathrm{Y}$ directions (Guest 2006). The detection of the gender of an individual based on his writing has also elicited different research works (Liwicki et al. 2007; Liwicki et al. 2011; Faundez-Zanuy and Sesa-Nogueras 2014) in which measurements such as word proportion, stroke formation, overall acceleration and writing direction have been considered. In these studies, particular movement parameters were considered such as mean velocity, acceleration, jerkiness, pen pressure, height, or horizontal length of tracings. While relevant and interesting, they do not consider the general shape of drawing/writing and their possible evolution with age or gender but propose summary parameters that may not characterize fully the global alteration of both geometric and kinematic parameters.

Several efficient models have been proposed in the literature to describe both the geometric and kinematic characteristics of drawing/handwriting in a common framework such as the Gaussian model (Plamondon 1989), the Sigma lognormal model (Plamondon et al. 2013) and the Beta elliptic model (Bezine et al. 2003; Kherallah et al. 2004; Boubaker et al. 2007). The latter has demonstrated its efficacy for both 2D writing ( Boubaker, Chaabouni, et al. 2013) and even 3D movement modeling (Boubaker et al. 2015). However, only young male adults were considered in these studies. Therefore, since handwriting and drawing movements may be influenced by 
age and gender, the question arises whether the Beta-elliptic model errors are also affected by these characteristics. In this case, it would be difficult to judge whether the differences in model parameters are due to the effect of aging, for example, or simply to differences induced by modeling errors. In this context, the objective of this work is to assess the Beta-elliptic model errors according to subject characteristics (age, gender, and level of writing activity) during a standardized ellipse drawing task in a sample of 99 participants with ages ranging from 19 to 85 years. It is hypothesized that the errors between measured and modeled trajectories are not affected by these individual characteristics.

\section{Materials and methods}

\subsection{The Beta-elliptic model}

The Beta-elliptic model for 2D writing movement consists in representing the trajectory by a combination of kinematic and geometric features (Bezine et al. 2003; Kherallah et al. 2004; Boubaker et al. 2007). It is widely used in several areas of research on online handwriting such as writer identification (Dhieb et al. 2021; Dhieb, Boubaker, et al. 2019; Dhieb et al. 2018) and handwriting recognition (Akouaydi et al. 2019; Hamdi et al. 2019; Hamdi et al. 2017). The curvilinear velocity profile of the movement is reconstructed by overlapped Beta functions (Alimi 1997) while the geometric representation is based on elliptic shapes. The combination of both types of features allows decomposing a complex trajectory in elementary parts called "strokes" between curvilinear velocity extrema: local maxima, local minima, and double inflection points. In the velocity domain, each stroke is described by a Beta impulse (1). The time instants $t_{0}, t_{c}$ and $t_{1}$ correspond to the starting time of the Beta function, the time of the 
maximum value noted $A$, and the ending time, respectively. $p$ and $q$ are refinement and asymmetry parameters (Fig. 1).

$$
\beta\left(K, t, q, p, t_{0}, t_{1}\right)=\left\{\begin{array}{l}
K \cdot\left(\frac{t-t_{0}}{t_{C}-t_{0}}\right)^{p} \cdot\left(\frac{t_{1}-t}{t_{1}-t_{C}}\right)^{q} \text { if } t \in\left[t_{0}, t_{1}\right] \\
0 \quad \text { elsewhere }
\end{array}\right\}
$$

\section{Please insert Fig. 1 around here}

The generation of a complete modeled curvilinear velocity profile $V_{R}(t)$ from a measured curvilinear velocity profile $V_{\sigma}(t)$ is the result of an algebraic addition of the overlapped Beta functions as shown in Eq. (2):

$$
V_{R}(t)=\sum_{i=1}^{n} V_{i}\left(t-t_{0 i}\right)=\sum_{i=1}^{n} p u l s e \beta_{i}\left(A_{i}, t, q_{i}, p_{i}, t_{0 i}, t_{1 i}\right)
$$

In the geometric domain, each stroke delimited between two successive points of curvilinear velocity extrema is modeled by an elliptic arc which parameters are $a, b, \theta$, and $\theta_{p}$ (greatest and lowest ellipse axes half-length, tilt, and angle of the tangent with respect to the horizontal at the extremity of the elliptic arc, respectively) (Fig. 2).

\section{Please insert Fig. 2 around here}

The details of the implementation of the Beta-elliptic model are presented in (Boubaker, Chaabouni, et al. 2013; Boubaker, Kherallah, et al. 2013).

\subsection{Definition of the modeling errors}

In order to quantify both geometric and kinematic modeling errors, the following parameters were considered. 


\subsubsection{Geometric errors}

The aim is to quantify the geometric discrepancy between the measured and modeled writing/drawing trajectories. In order to assess these errors, the notion of deviation radius is used. Let us consider a point $M_{i}$ on the measured trajectory and the line $\left[C_{\text {arc }} M_{i}\right)$ originating from the center of the modeled elliptic arc $C_{a r c}$ and passing through $M_{i}$ (dashed segment of Fig. 3). Let $N_{i}$ be the intersection point of the modeled elliptic trajectory and $\left[C_{a r c} M_{i}\right)$. The deviation radius is the length of the segment $\left[M_{i} N_{i}\right]$. The greater the deviation radius the greater the geometric error (Fig. 3).

\section{Please insert Fig. 3 around here}

The following absolute (in $\mathrm{mm}$ ) and relative (in \% of arc length) reconstruction errors are evaluated:

- Average absolute geometric error ( $\mathrm{mm})$ :

$$
A v e_{-} E r r=\frac{1}{K} \sum_{k=1}^{K} A v e_{-} E r r_{k}
$$

with $A v e_{-} \operatorname{Err}_{k}=\frac{1}{n_{k}} \sum_{i=1}^{n_{k}}\left\|M_{i} N_{i}\right\|$ is the average error for stroke $k$.

$K$ is the total number of elliptic arcs or Beta strokes and $n_{k}$ is the number of samples of stroke $k$.

- Maximum absolute geometric error $(\mathrm{mm})$ :

$$
\text { Max_Err }=\max _{i=1}^{N}\left(\left\|M_{i} N_{i}\right\|\right)
$$

- Average relative geometric error in \% (the average error is normalized by the arc length): 


$$
\text { Ave_Err } \%=\frac{1}{K} \sum_{k=1}^{K} \frac{A v e_{-} E r r_{k}}{\left\|M_{1} M_{n_{k}}\right\|} \times 100
$$

- Maximum relative geometric error in percent:

$$
M a x_{-} E r r \%=\max _{k=1}^{K}\left(\frac{\text { Max_Err }}{\left\|M_{1} M_{n_{k}}\right\|}\right) \times 100
$$

Max_Err $k$ is the maximum error for stroke $k$ and $N$ is the total number of samples of the $K$ strokes, $N=K \times n_{k}$.

Also, in order to assess the level of curvature conformity, the curvature radius $R_{C_{-} M i}$ is computed at each point $M_{i}$ of the trajectory and compared to the $R_{C_{-} N i}$ curvature radius measured at the corresponding point $N_{i}$ on the elliptic arc. The difference between the two values represents the curvature radius error at the point $M_{i} . R_{\mathcal{C}_{-} M i}$ is defined as following (the same technique is used to define $R_{C_{-} N i}$, the curvature radius of the modeled trajectory):

$$
R_{c_{-} M i}=\frac{\Delta \ell_{i}}{\Delta \theta_{i}}=\frac{\left\|M_{i} M_{i-1}\right\|}{\left|\theta_{i}-\theta_{i-1}\right|}
$$

$\theta_{i}$ and $\theta_{i-1}$ are the angles between the tangent to the trajectory and the horizontal axis at sample points $i$ and $i-1$, respectively. The absolute average and maximum values of this error and the relative average curvature error in percent are then evaluated:

- Average absolute curvature error ( $\mathrm{mm})$ :

$$
\text { Ave_Cur_Err }=\frac{1}{N} \cdot \sum_{i=1}^{N}\left|R_{c_{-} M i}-R_{c_{-} N i}\right|
$$

- Average relative curvature error (\%): 


$$
A v e_{-} C u r_{-} E r r \%=\frac{1}{N} \sum_{i=1}^{N} \frac{\left|R_{c_{-} M i}-R_{c_{-} N i}\right|}{R_{c_{-} M i}} \times 100
$$

- Maximum curvature error ( $\mathrm{mm})$ :

$$
M a x_{-} C u r_{-} E r r=\max _{i=1}^{N}\left|R_{c_{-} M i}-R_{c_{-} N i}\right|
$$

\subsubsection{Velocity errors}

For each time step, the curvilinear velocity error was assessed by considering the measured $V_{\sigma}(t)$ and modeled $V_{R}(t)$ velocity profiles, respectively:

$$
\begin{aligned}
& E r r_{-} V\left(t_{i}\right)=\left|V_{\sigma}\left(t_{i}\right)-V_{R}\left(t_{i}\right)\right| \\
& E r r \%_{-} V\left(t_{i}\right)=\frac{\left|V_{\sigma}\left(t_{i}\right)-V_{R}\left(t_{i}\right)\right|}{V_{\sigma}\left(t_{i}\right)} \times 100
\end{aligned}
$$

$V_{R}\left(t_{i}\right)$ and $V_{\sigma}\left(t_{i}\right)$ are the modeled and measured curvilinear velocity values at sample $i$, respectively. Then, the average error over the whole trajectory ( $N$ samples) was assessed:

$$
\begin{aligned}
& A v e_{-} E r r_{-} V=\frac{1}{N} \sum_{i=1}^{N} E r r_{-} V\left(t_{i}\right) \\
& A v e_{-} E r r \%_{-} V=\frac{1}{N} \sum_{i=1}^{N} E r r \%_{-} V\left(t_{i}\right)
\end{aligned}
$$

The maximum error of reconstruction as shown in Fig. 4 was also assessed:

$$
\begin{aligned}
& M a x_{-} E r r_{-} V=\max _{i=1}^{N}\left(E r r_{-} V\left(t_{i}\right)\right) \\
& M a x_{-} E r r \%_{-} V=\max _{i=1}^{N}\left(E r r \%_{-} V\left(t_{i}\right)\right)
\end{aligned}
$$


Finally, the Signal to Noise Ratio $\left(S N R_{v t}\right)$ was assessed (O'Reilly and Plamondon 2009).

$$
S N R_{v t}=20 \log \left(\frac{\int_{0}^{t_{e}} V_{\sigma}^{2}(t) d t}{\int_{0}^{t_{e}}\left(V_{\sigma}(t)-V_{R}(t)\right)^{2} d t}\right)
$$

$t_{e}$ is the movement duration. The greater the $S N R_{v t}$ is the better the model estimates the measured velocity profile.

\subsection{Experiment}

Although several databases of handwriting movements have been created so far (Zarro and Anwer 2017; Manjusha et al. 2019), none of them were specifically designed for studying the effect of modeling errors according to individual characteristics during ellipse drawing. The choice of the ellipse is justified by the fact that several works assume that the writing trajectory can be assimilated to a concatenation of elliptic arcs (Marcelli et al. 2013). Indeed, the elliptic shape of planar hand movement strokes defined between two successive curvilinear velocity extrema is related to the bell-shape (Plamondon 1989; Plamondon et al. 2013) or sinusoidal nature (Eden 1962; Hollerbach 1981) of the velocity components through the two-third power law. Let us admit that the trajectory segment satisfies this law $(18)\left(R_{C}(t)\right.$ is the radius of curvature),

$$
\mathrm{V}_{\sigma}(\mathrm{t})=\mathrm{A} \cdot\left(\mathrm{R}_{\mathrm{C}}(\mathrm{t})\right)^{1 / 3}
$$

and that the coordinates of the curvilinear velocity present a sinusoidal shape such that:

$$
\mathrm{V}_{\sigma}^{2}(\mathrm{t})=a^{2} \cdot \cos ^{2}(\alpha(\mathrm{t}))+\mathrm{b}^{2} \cdot \sin ^{2}(\alpha(\mathrm{t}))
$$

and if we assume $\mathrm{A}=(a \cdot \mathrm{b})^{1 / 3}$

We obtain $\frac{\mathrm{V}_{\sigma}(\mathrm{t})}{R_{C}(\mathrm{t})}=\mathrm{V}_{\theta}(\mathrm{t})=\frac{a \cdot b}{a^{2} \cdot \cos ^{2}(\alpha(\mathrm{t}))+\mathrm{b}^{2} \cdot \sin ^{2}(\alpha(\mathrm{t}))}$ 
which means that the trajectory strictly follows the angular characteristic of an ellipse. $\alpha(t)$ is a continuous function. In addition, the ellipse is easier to draw at different ages and can be executed by participants who did not learn to write. For this reason, a new database called RETED (REgim Tunisian Ellipse Drawing database) was built. More details are provided in the next sub-section.

\subsubsection{Participants}

Ninety-nine participants voluntarily took part in the database construction. Their age ranged from 19 to 85 years: 33 participants in the range $[19,39]$ years, 33 in the range $[40,59]$ and 33 in the range $[60,85]$. Thirty women (range 19-72 years) and sixty-nine men (range 25-85 years) participated. The distribution of participants with age and gender is displayed in Fig. 5 and detailed in Table 1. The oldest participants were recruited in retirement homes in the towns of Tunis, Sfax, and Gafsa in Tunisia. The participants' health status was checked based on their self-report and on the indications of the retirement homes staff. The experimental protocol followed the declaration of Helsinki and was approved by the local ethics committee. Written informed consent was obtained from each participant. For those who cannot read due to illiteracy, the consent form was read aloud, and the participant confirmed his or her approval verbally and with a sign on the consent form. The non-inclusion criteria were any neurodegenerative or musculoskeletal pathology that could affect the understanding of the instructions and the ability to draw. The participants had normal or corrected to normal vision.

\section{Please insert Fig. 5 around here}

\section{Please insert Table 1 around here}




\subsubsection{Experimental protocol}

During data acquisition, participants were seated in a comfortable chair with a seat height of $45 \mathrm{~cm}$ and a backrest while keeping their elbow in contact with a table $80 \mathrm{~cm}$ high. The height of the chair and the table were not adjustable. The participants were asked to perform a repetitive tracing of an ellipse on a graphical tablet with its stylus (GENIUS MousePen i608X, KYE Systems Europe GmbH, Langenfeld, Germany) for 60 seconds (Fig. 6). The graphical tablet was positioned horizontally on the table. The model of the ellipse was drawn on a sheet of paper placed on top of the tablet. The experimenter verified that the participants were correctly seated and felt comfortable drawing on the graphical tablet. In addition, and in order to ensure that the participants had well understood the requested movement, the experimenter displayed the task with the stylus. The participants were allowed to practice the task before data recording for three minutes. The experimenter verified that the participants' posture was correct and that the instructions were well understood. The participants were asked to execute the movement at their preferred speed and no instruction on movement velocity was given. A custom-made software developed in MATLAB (MathWorks, Natick MA, USA) was used to record the data. The list of $2 \mathrm{D}$ coordinates sampled at $100 \mathrm{~Hz}$ was filtered using a Chebyshev low pass filter (type 2) with a cut-off frequency of $10 \mathrm{~Hz}$ in accordance with handwriting frequency ripple. The first and the last Beta impulses were not considered because the calculation of the reconstructed velocity in these two cases is taken by a single impulse and not the sum of the two overlapped impulses. The characteristics of the ellipse were: long axis $=60 \mathrm{~mm}$, small axis $=36 \mathrm{~mm}$, inclination of the major axis $\theta=30^{\circ}$ as shown in the top right corner of Fig. 6 . The configuration of the data acquisition system is presented in Fig. 6. In addition, each participant was asked to self-evaluate her(his) level of writing activity between frequent, occasional, or rare. 


\section{Please insert Fig. 6 around here}

\subsubsection{Statistics}

The signal was modeled with the Beta-elliptic model and the error parameters listed in section 2.2. were evaluated. The Pearson correlation coefficients between the errors and movement mean velocity as well as age were computed. In addition, the correlation between age and movement velocity was assessed. An ANCOVA with mean velocity as covariate was used to assess the effect of gender and level of writing activity. Tukey post-hoc tests were used. For the dependent variables (DV) for which the hypothesis of normality (Shapiro-Wilk test) and homogeneity of variance (Levene's test) were not met, non-parametric tests were used: Wilcoxon-Mann-Whitney for gender and KruskalWallis for the level of writing activity. The level of significance was set to 0.05 . A twoway ANCOVA (Gender $\times$ activity of writing) was not considered since the sizes of some of the resulting groups were low (7 participants) and differed too much between groups (from 7 to 30). All statistical analyses were conducted in Statistica (Statsoft, Tulsa, OK, USA).

\section{Results}

Fig. 7 presents examples of Beta-elliptic modeling of two short trajectory samples from a subject aged 20 years (Fig. 7.A, B and C) and 85 years (Figure 7.D, E and F). Fig. 8 and 9 present the average relative geometric and velocity errors according to age and gender, respectively. The geometric and velocity profile reconstruction errors are presented in Table 2.

Please insert Table 2 around here

Please insert Fig. 7 around here 
The correlation coefficients between age, velocity and the error parameters are presented in Table 3. The Ave-Err-V is significantly correlated with both age and movement velocity. Average and maximal absolute curvature errors are negatively correlated with velocity while average and maximal absolute velocity errors are positively correlated with velocity $(\mathrm{p}<0.05)$. Overall, the correlations appear low (max $0.33)$. No relative error is correlated neither with velocity nor age. The $\mathrm{SNR}_{\mathrm{vt}}$ is not correlated significantly either with age or velocity. Movement velocity and age were significantly correlated $(\mathrm{r}=-0.63, \mathrm{p}<0.001)$.

The geometric and velocity errors according to gender and writing activity level are presented in Tables 4 and 5, respectively. For gender, all errors were tested with parametric tests (Table 6) and no significant differences were found for any of the errors considering the velocity as covariate except Ave_Cur_Err\% which was lower for female compared to male participants but with very low and close values $(0.44(0.10) \%$ vs $0.49(0.13) \%, \mathrm{p}<0.05)($ Table 4$)$ and $\mathrm{SNR}_{\mathrm{vt}}$ which was significantly greater for female participants compared to male participants $(\mathrm{p}<0.05)$ (Table 5). For the level of writing activity, parametric tests were conducted for Ave_Err\%, Max_Err\%, Ave_Cur_Err AveCur-Err\%, Ave-Err-V, Ave-Err\%-V, Max-Cur-Err\% (Table 6) and non-parametric tests for the remaining variables: Ave_Err, Max_Err, Max-Cur-Err (Table 7). Concerning, the writing activity level, Ave-Cur-Err was significantly greater for occasional compared to frequent $(\mathrm{p}<0.05)$ and Tukey post-hoc tests revealed that Ave-Err-V was significantly greater for frequent relative to occasional or rare $(\mathrm{p}<0.05)$ although the ANCOVA results were not significant for this dependent variable (Table 4). On the contrary, the ANCOVA for Max_Err\% was significant while post-hoc tests were not. These mismatches were only found for Max-Err\% (Table 4) and Ave-Err-V (Table 5).

\section{Please insert Table 3 around here}




\section{Please insert Table 4 around here}

\section{Please insert Table 5 around here}

Please insert Table 6 around here

Please insert Table 7 around here

Please insert Fig. 8 around here

Please insert Fig. 9 around here

\section{Discussion}

This paper aimed to study the effect of individual characteristics (age, gender, and level of writing activity) on the Beta-elliptic model errors during an ellipse drawing task. To this end, a database of repetitive elliptical drawing movements (RETED) was built within a sample of 99 participants regularly distributed between the ages of 19 and 85 years.

Results indicated a non-significant correlation between relative modeling errors and age or movement velocity. Although the correlation coefficients between curvilinear velocity and absolute velocity errors were significant, they remained low in value and all relative errors displayed non-significant correlations.

The fact that average absolute velocity error decreased with age seems to be due to the fact that the movement velocity also decreased significantly with age. Therefore, movement velocity seemed to be the major factor affecting modeling errors. The quality of curvature estimation is lowest in the presence of double inflection points. These points appear mainly in the case of low-velocity movements. This may explain why the curvature error was negatively correlated with the velocity. The absolute velocity error was also significantly different between levels of writing activity. This is due to the fact, 
that the writing activity level displayed an age dependency (Fig. 10 and 11) with younger participants presenting a greater writing activity than the elderly.

\section{Please insert Fig. 10 around here}

\section{Please insert Fig. 11 around here}

Gender seemed not to influence modeling errors with no significant difference between male and female participants except for $\mathrm{SNR}_{\mathrm{vt}}$ which showed that the velocity profile was better reconstructed for female than male participants. All-in-all, the modeling errors were not affected by individual characteristics such as age, gender or writing activity level except for absolute average velocity error and therefore we considered that the research hypothesis was validated. Only absolute errors were affected by movement velocity but presented a low correlation coefficient.

Concerning the curvilinear velocity error amplitude, the average SNRvt (68.79) is better than those reported in several studies on writing based on the Sigma-Lognormal model with values of 34.7 (O’Reilly and Plamondon 2009) and 30.3 (Laurent et al. 2020). Also, the performances of a multi-component sinusoidal model applied on the SVC2004 Task 2 database (Choudhury and Prasanna 2019) presented greater horizontal (SNRvt $=$ 40.39) and vertical $(\mathrm{SNRvt}=44.85)$ velocity errors in comparison to the present study. The fact that the shape to be drawn was a simple ellipse may explain the better results in comparison to the more complex writing movements considered in these studies. The relative velocity error $(8.79 \%)$, the average relative curvature and geometric errors of $0.48 \%$ and $0.68 \%$ respectively appeared low.

This study can be extended to examine the variability of the model error on the trajectories of different geometric shapes and during writing. In such cases, the corpus of volunteer participants should be restricted to educated participants of different ages 
and genders to test other forms such as symbols. Furthermore, we believe that the proposed study can be further improved by considering other individual characteristics such as hand dominance.

The proposed modeling approach seems suitable for studying the effect of age on drawing/writing movements parameters because the modeling errors seem not to be influenced by this characteristic. Therefore, observed variations in the model parameters could be attributed to the effect of age and not to the modeling errors. This opens the way for interesting applications such as signature recognition at different ages taking into account the writing evolution. Also, if the variation of parameters can be identified in the case of healthy aging, a deviation from this normal evolution could be attributed to a pathology affecting the sensory-motor system. Such deviation could constitute an interesting tool for neurodegenerative disease early detection (De Stefano et al. 2019). The question arises whether drawing on a tablet may alter the geometrical and kinematical characteristics due to differences in surface texture or friction. Previous studies (Gerth, Klassert, et al. 2016; Gerth, Dolk, et al. 2016) showed that movement velocity increased when drawing on a tablet in comparison to drawing on paper possibly due to the smoother surface characteristics of the tablet surface compared to paper. However, it was also shown that adults rapidly adapted to the tablet surface characteristics. In the present protocol, a sheet of paper on which the model of the ellipse to be drawn was printed was placed on top of the tablet. The fact that a stylus was used instead of a pen may have altered the friction characteristics slightly, but the difference is certainly smaller than that between paper and a pen and that between the smooth surface of the tablet and its stylus. 


\section{Conclusion}

In this paper, we investigated whether some individual characteristics such as age, gender and level of writing activity have an influence on the Beta-elliptic model errors during ellipse drawing modeling. Except for curvature and absolute velocity errors, both the obtained average absolute and relative geometric and velocity errors revealed a nonsignificant correlation between modeling errors and subject characteristics.

Consequently, the Beta-elliptic model might be used for handwriting analysis, being an interesting solution to challenging problems in this domain such as evaluating the effects of aging and detecting motor planning disorders and neurodegenerative disease.

\section{Acknowledgments}

The research leading to these results has received funding from the Ministry of Higher Education and Scientific Research of Tunisia under the grant agreement number LR11ES4.

\section{Declaration of interest statement}

The authors have no conflict of interest to declare.

\section{References}

Akouaydi H, Njah S, Ouarda W, Samet A, Dhieb T, Zaied M, Alimi AM. 2019. Neural Architecture based on Fuzzy Perceptual Representation For Online Multilingual Handwriting Recognition. arXiv:190800634.

Alimi AM. 1997. An evolutionary neuro-fuzzy approach to recognize on-line Arabic handwriting. In: Proceedings of the Fourth International Conference on Document Analysis and Recognition; Aug 18-20; Ulm, Germany. p. 382-386.

Bezine H, Alimi AM, Derbel N. 2003. Handwriting trajectory movements controlled by a beta-elliptical model. In: Proceedings of the Seventh International Conference on Document Analysis and Recognition; Aug 3-6; Edinburgh, Scotland. p. 1228-1232.

Boubaker H, Chaabouni A, Tagougui N, Kherallah M, Alimi AM. 2013. Handwriting and hand drawing velocity modeling by superposing beta impulses and continuous training component. International Journal of Computer Science Issues (IJCSI). 10(5): 57-63.

Boubaker H, Kherallah M, Alimi A. 2007. New Strategy for the On-Line Handwriting Modelling. In: Proceedings of the Ninth International Conference on Document Analysis and Recognition; Sep 23-26; Paraná, Brazil. p. 1233-1247. 
Boubaker H., Kherallah M, Alimi AM. 2013. Optimization of the beta-elliptic model features estimation. In: Proceedings of the 16th International Conference of Graphonomix Society (IGS'13); June 2013; Nara, Osaka, Japan: International Graphonomix Society. p. 151-154.

Boubaker H, Rezzoug N, Kherallah M, Gorce P, Alimi AM. 2015. Spatiotemporal representation of 3D hand trajectory based on beta-elliptic models. Computer Methods in Biomechanics and Biomedical Engineering. 18(15):1632-1647.

Burger DK, McCluskey A. 2011. Australian norms for handwriting speed in healthy adults aged 60-99 years. Australian Occupational Therapy Journal. 58(5):355-363.

Caligiuri MP, Kim C, Landy KM. 2014. Kinematics of Signature Writing in Healthy Aging. Journal of Forensic Sciences. 59(4):1020-1024.

Choudhury H, Prasanna SRM. 2019. Representation of online handwriting using multicomponent sinusoidal model. Pattern Recognition. 91:200-215.

De Stefano C, Fontanella F, Impedovo D, Pirlo G, Scotto di Freca A. 2019. Handwriting analysis to support neurodegenerative diseases diagnosis: A review. Pattern Recognition Letters. 121:37-45.

Dhieb T, Boubaker H, Ouarda W, Ayed MB, Alimi AM. 2019. Deep Bidirectional Long Short-Term Memory for Online Arabic Writer Identification Based on Beta-Elliptic Model. In: Proceedings of the 2019 International Conference on Document Analysis and Recognition Workshops; Sep 22-25; Sydney, Australia. p. 35-40.

Dhieb T, Boubaker H, Ouarda W, Njah S, Ben Ayed M, Alimi AM. 2021. Deep bidirectional long short-term memory for online multilingual writer identification based on an extended Beta-elliptic model and fuzzy elementary perceptual codes. Multimed Tools Appl. 80(9):14075-14100.

Dhieb T, Njah S, Boubaker H, Ouarda W, Ayed MB, Alimi AM. 2018. An online writer identification system based on beta-elliptic model and fuzzy elementary perceptual codes. arXiv preprint arXiv: 180405661.

Dhieb T, Njah S, Boubaker H, Ouarda W, Ben Ayed M, Alimi AM. 2020. Towards a novel biometric system for forensic document examination. Computers \& Security. 97:101973.

Dhieb T, Rezzoug N, Boubaker H, Gorce P, Alimi AM. 2019. Effect of age on hand drawing movement kinematics. Computer Methods in Biomechanics and Biomedical Engineering. 22(sup1):S188-S190.

Dixon RA, Kurzman D, Friesen IC. 1993. Handwriting performance in younger and older adults: Age, familiarity, and practice effects. Psychology and Aging. 8(3):360 370 .

Eden M. 1962. Handwriting and pattern recognition. IRE Transactions on Information Theory. 8(2):160-166. 
Faundez-Zanuy M, Sesa-Nogueras E. 2014. Preliminary Experiments on Automatic Gender Recognition Based on Online Capital Letters. Recent Advances of Neural Network Models and Applications. Cham: Springer. 26:363-370.

Gerth S, Dolk T, Klassert A, Fliesser M, Fischer MH, Nottbusch G, Festman J. 2016. Adapting to the surface: A comparison of handwriting measures when writing on a tablet computer and on paper. Human Movement Science. 48:62-73.

Gerth S, Klassert A, Dolk T, Fliesser M, Fischer MH, Nottbusch G, Festman J. 2016. Is Handwriting Performance Affected by the Writing Surface? Comparing Preschoolers', Second Graders', and Adults' Writing Performance on a Tablet vs. Paper. Frontiers in Psychology 7, 1308: 1-18.

Guest R. 2006. Age dependency in handwritten dynamic signature verification systems. Pattern Recognition Letters. 27(10):1098-1104.

Hamdi Y, Boubaker H, Dhieb T, Elbaati A, Alimi AM. 2019. Hybrid DBLSTM-SVM Based Beta-Elliptic-CNN Models for Online Arabic Characters Recognition. In: Proceedings of the 2019 International Conference on Document Analysis and Recognition; Sep 22-25; Sydney, Australia. p. 545-550.

Hamdi Y, Chaabouni A, Boubaker H, Alimi AM. 2017. Off-lexicon online Arabic handwriting recognition using neural network. In: Proceedings of the Ninth International Conference on Machine Vision; Nov 18-20; Nice, France. p. 103410G.

Hollerbach JM. 1981. An oscillation theory of handwriting. Biol Cybern. 39(2):139156.

Kherallah M, Haddad L, Alimi AM, Mitiche A. 2004. Towards the design of handwriting recognition system by neuro-fuzzy and beta-elliptical approaches. In: Proceedings of the Artficial Intelligence Applications \& Innovations (AIAI), 18th IFIP World Computer Congress; Aug 22-27; Toulouse, France. p. 187-196.

Kumar R, Chanda B, Sharma JD. 2014. A novel sparse model based forensic writer identification. Pattern Recognition Letters. 35:105-112.

Laurent A, Plamondon R, Begon M. 2020. Central and Peripheral Shoulder Fatigue Prescreening Using the Sigma-Lognormal Model: A Proof of Concept. Front Hum Neurosci. 14:1-16.

Liwicki M, Schlapbach A, Bunke H. 2011. Automatic gender detection using on-line and off-line information. Pattern Anal Applic. 14(1):87-92.

Liwicki M, Schlapbach A, Loretan P, Bunke H. 2007. Automatic Detection of Gender and Handedness from On-Line Handwriting. In: Proceedings of the 13th Conf of the Graphonomics Society; Nov 11-14; Melbourne, Australia. p. 179-183.

Manjusha K, Kumar MA, Soman KP. 2019. On developing handwritten character image database for Malayalam language script. Engineering Science and Technology, an International Journal. 22(2):637-645. 
Marcelli A, Parziale A, Santoro A. 2013. Modelling Visual Appearance of Handwriting. In: Proceedings of the International Conference on Image Analysis and Processing; Sep 11-13; Naples, Italy. p. 673-682.

O’Reilly C, Plamondon R. 2009. Development of a Sigma-Lognormal representation for on-line signatures. Pattern Recognition. 42(12):3324-3337.

Parziale A, Diaz M, Ferrer MA, Marcelli A. 2019. SM-DTW: Stability Modulated Dynamic Time Warping for signature verification. Pattern Recognition Letters. 121:113-122.

Plamondon R. 1989. Handwriting control: a functional model. In Rodney M. J. Cotterill (ed.), Models of Brain Function. Cambridge University Press. p. 563-574.

Plamondon R, O'Reilly C, Rémi C, Duval T. 2013. The lognormal handwriter: learning, performing, and declining. Front Psychol. 4:1-14

Rodríguez-Aranda C. 2003. Reduced Writing and Reading Speed and Age-related Changes in Verbal Fluency Tasks. The Clinical Neuropsychologist. 17(2):203-215.

Rosenblum S, Werner P. 2006. Assessing the handwriting process in healthy elderly persons using a computerized system. Aging Clin Exp Res. 18(5):433-439.

Seidler RD, Bernard JA, Burutolu TB, Fling BW, Gordon MT, Gwin JT, Kwak Y, Lipps DB. 2010. Motor control and aging: Links to age-related brain structural, functional, and biochemical effects. Neuroscience \& Biobehavioral Reviews. 34(5):721-733.

Zarro RD, Anwer MA. 2017. Recognition-based online Kurdish character recognition using hidden Markov model and harmony search. Engineering Science and Technology, an International Journal. 20(2):783-794. 
Table 1. Characteristics of the participants

\begin{tabular}{|c|c|c|}
\hline Characteristics & Value & $\begin{array}{l}\text { Number of } \\
\text { participants }\end{array}$ \\
\hline \multirow[t]{3}{*}{ Age } & {$[19,39]$ years } & 33 \\
\hline & {$[40,59]$ years } & 33 \\
\hline & {$[60,85]$ years } & 33 \\
\hline \multirow[t]{2}{*}{ Gender } & Women & 30 \\
\hline & Men & 69 \\
\hline \multirow[t]{2}{*}{ Dominant hand } & Right-handed & 96 \\
\hline & Left-handed & 3 \\
\hline \multirow{3}{*}{$\begin{array}{l}\text { Level of writing } \\
\text { activity }\end{array}$} & Frequent & 33 \\
\hline & Occasional & 27 \\
\hline & Rare & 38 \\
\hline
\end{tabular}


Table 2. Geometric and velocity profile reconstruction absolute and relative errors

\begin{tabular}{cccc}
\hline Type of error & Mean & $\begin{array}{c}\text { Standard Deviation } \\
\text { (SD) }\end{array}$ & $\begin{array}{c}95 \% \text { Confidence } \\
\text { interval }\end{array}$ \\
\hline Ave_Err (mm) & 0.27 & 0.10 & {$[0.25,0.29]$} \\
Ave_Err\% (\%) & 0.68 & 0.14 & {$[0.65,0.71]$} \\
Max_Err (mm) & 0.61 & 0.22 & {$[0.57,0.65]$} \\
Max_Err\% (\%) & 1.53 & 0.34 & {$[1.46,1.60]$} \\
Ave_Cur_Err (mm) & 4.54 & 2.19 & {$[4.11,4.97]$} \\
Ave_Cur_Err\% (\%) & 0.48 & 0.12 & {$[0.46,0.50]$} \\
Max_Cur_Err (mm) & 5.79 & 2.60 & {$[5.28,6.30]$} \\
Max_Cur_Err\% (\%) & 8.28 & 3.70 & {$[7.55,9.01]$} \\
Ave_Err_V (mm/s) & 4.68 & 2.73 & {$[4.14,5.22]$} \\
Ave_Err\%_V (\%) & 8.79 & 1.90 & {$[8.41,9.16]$} \\
Max_Err_V (mm/s) & 8.81 & 5.95 & {$[7.64,9.98]$} \\
Max_Err\%_V $(\%)$ & 14.08 & 4.63 & {$[13.17,14.99]$} \\
SNRvt (dB) & 68.79 & 17.59 & {$[65.33,72.26]$} \\
\hline
\end{tabular}


Table 3. Pearson correlation coefficients between errors and mean curvilinear velocity and age (bold and red text: $\mathrm{p}<0.05$ )

\begin{tabular}{ccccc}
\hline r & \multicolumn{2}{c}{ Age } & \multicolumn{2}{c}{ Velocity } \\
\hline Ave_Err (mm) & -0.05 & $\mathrm{p}=.607$ & 0.14 & $\mathrm{p}=.170$ \\
Ave_Err\% (\%) & 0.08 & $\mathrm{p}=.437$ & -0.03 & $\mathrm{p}=.794$ \\
Max_Err (mm) & -0.06 & $\mathrm{p}=.562$ & 0.14 & $\mathrm{p}=.159$ \\
Max_Err\% (\%) & 0.07 & $\mathrm{p}=.499$ & -0.06 & $\mathrm{p}=.541$ \\
Ave_Cur_Err (mm) & 0.15 & $\mathrm{p}=.144$ & $\mathbf{- 0 . 2 2}$ & $\mathrm{p}=. \mathbf{0 2 5}$ \\
Ave_Cur_Err\% (\%) & 0.04 & $\mathrm{p}=.694$ & -0.04 & $\mathrm{p}=.728$ \\
Max_Cur_Err (mm) & 0.13 & $\mathrm{p}=.184$ & $\mathbf{- 0 . 2 2}$ & $\mathrm{p}=. \mathbf{0 2 6}$ \\
Max_Cur_Err\% (\%) & 0.17 & $\mathrm{p}=.100$ & -0.13 & $\mathrm{p}=.188$ \\
Ave_Err_V (mm/s) & $-\mathbf{0 . 2 8}$ & $\mathrm{p}=.006$ & $\mathbf{0 . 3 3}$ & $\mathrm{p}=.001$ \\
Ave_Err\%_V (\%) & -0.13 & $\mathrm{p}=.190$ & 0.15 & $\mathrm{p}=.126$ \\
Max_Err_V (mm/s) & -0.14 & $\mathrm{p}=.164$ & $\mathbf{0 . 2 3}$ & $\mathrm{p}=. \mathbf{0 2 1}$ \\
Max_Err\%_V (\%) & 0.08 & $\mathrm{p}=.449$ & -0.01 & $\mathrm{p}=.932$ \\
SNRvt (dB) & -0.14 & $\mathrm{p}=.168$ & 0.07 & $\mathrm{p}=.465$ \\
\hline
\end{tabular}


Table 4. Mean (SD) of geometric absolute and relative errors according to gender and writing activity level (bold $p<0.05$ ). Superscript " $a$ " means that the value is significantly different from Frequent, " $b$ " from occasional and "c" from rare $(\mathrm{p}<0.05)$

\begin{tabular}{|c|c|c|c|c|c|c|c|c|c|}
\hline $\begin{array}{c}\text { Character } \\
\text { istics }\end{array}$ & Value & $\underset{(\mathrm{mm})}{\text { Ave_Err }}$ & $\begin{array}{c}\text { Ave_Err } \\
\%\end{array}$ & $\underset{(\mathrm{mm})}{\operatorname{Max} E r r}$ & $\underset{\%}{\operatorname{Max} \_ \text {Err }}$ & $\begin{array}{c}\text { Ave Cur } \\
\text { Err } \\
(\mathrm{mm})\end{array}$ & $\begin{array}{c}\text { Ave_Cur } \\
\text { Err\% } \\
\text { (\%) }\end{array}$ & $\begin{array}{c}\text { Max Cur } \\
\text { Err } \\
(\mathrm{mm})\end{array}$ & $\begin{array}{c}\text { Max_Cur } \\
\text { Err\% } \\
(\%)\end{array}$ \\
\hline \multirow[t]{2}{*}{ Gender } & Men & $\begin{array}{c}0.28 \\
(0.11)\end{array}$ & $\begin{array}{c}0.67 \\
(0.13)\end{array}$ & $\begin{array}{c}0.62 \\
(0.22)\end{array}$ & $\begin{array}{l}1.50 \\
(0.30)\end{array}$ & $\begin{array}{c}4.33 \\
(1.96)\end{array}$ & $\begin{array}{c}0.49 \\
(0.13)\end{array}$ & $\begin{array}{c}5.67 \\
(2.39)\end{array}$ & $\begin{array}{c}8.16 \\
(3.60)\end{array}$ \\
\hline & Women & $\begin{array}{c}0.26 \\
(0.10)\end{array}$ & $\begin{array}{c}0.69 \\
(0.15)\end{array}$ & $\begin{array}{c}0.58 \\
(0.22)\end{array}$ & $\begin{array}{l}1.60 \\
(0.41)\end{array}$ & $\begin{array}{c}4.74 \\
(2.64)\end{array}$ & $\begin{array}{c}0.44 \\
(0.10)\end{array}$ & $\begin{array}{c}6.09 \\
(3.10)\end{array}$ & $\begin{array}{c}8.54 \\
(4.03)\end{array}$ \\
\hline \multirow{3}{*}{$\begin{array}{l}\text { Writing } \\
\text { activity } \\
\text { level }\end{array}$} & $\begin{array}{l}\text { Frequent } \\
\text { (a) }\end{array}$ & $\begin{array}{c}0.28 \\
(0.07)\end{array}$ & $\begin{array}{c}0.66 \\
(0.14)\end{array}$ & $\begin{array}{c}0.63 \\
(0.15)\end{array}$ & $\begin{array}{l}1.49 \\
(0.33)\end{array}$ & $\begin{array}{c}3.87 \\
(1.67)^{b}\end{array}$ & $\begin{array}{c}0.48 \\
(0.14)\end{array}$ & $\begin{array}{c}5.34 \\
(2.46)\end{array}$ & $\begin{array}{c}7.65 \\
(3.05)\end{array}$ \\
\hline & $\begin{array}{l}\text { Occasional } \\
\text { (b) }\end{array}$ & $\begin{array}{c}0.27 \\
(0.10)\end{array}$ & $\begin{array}{c}0.72 \\
(0.15)\end{array}$ & $\begin{array}{c}0.60 \\
(0.21)\end{array}$ & $\begin{array}{l}1.65 \\
(0.41)\end{array}$ & $\begin{array}{c}5.29 \\
(\mathbf{3 . 1 6})^{\mathrm{a}}\end{array}$ & $\begin{array}{c}0.48 \\
(0.12)\end{array}$ & $\begin{array}{l}6.36 \\
(3.47)\end{array}$ & $\begin{array}{c}9.41 \\
(4.21)\end{array}$ \\
\hline & Rare (c) & $\begin{array}{c}0.26 \\
(0.13)\end{array}$ & $\begin{array}{c}0.66 \\
(0.13)\end{array}$ & $\begin{array}{c}0.59 \\
(0.28)\end{array}$ & $\begin{array}{c}1.47 \\
(0.28)\end{array}$ & $\begin{array}{l}4.40 \\
(1.52)\end{array}$ & $\begin{array}{c}0.47 \\
(0.11)\end{array}$ & $\begin{array}{c}5.80 \\
(1.96)\end{array}$ & $\begin{array}{c}8.03 \\
(3.80)\end{array}$ \\
\hline
\end{tabular}


Table 5. Velocity reconstruction errors according to the participants' characteristics.

Superscript "a" means that the value is significantly different from Frequent, "b" from occasional and "c" from rare

\begin{tabular}{ccccccc}
\hline Characteristics & Value & $\begin{array}{c}\text { Ave_Err_V } \\
(\mathrm{mm} / \mathrm{s})\end{array}$ & $\begin{array}{c}\text { Ave_Err\%_V } \\
(\%)\end{array}$ & $\begin{array}{c}\text { Max_Err_V } \\
(\mathrm{mm} / \mathrm{s})\end{array}$ & Max_Err\%_V (\%) & SNRvt (dB) \\
\hline Gender & Men & $4.42(2.66)$ & $8.65(2.03)$ & $8.21(5.66)$ & $14.13(4.88)$ & $\mathbf{6 6 . 2 8 ( 1 7 . 4 0 )}$ \\
& Women & $5.28(2.85)$ & $9.10(1.60)$ & $10.18(6.56)$ & $13.97(4.15)$ & $\mathbf{7 4 . 5 4 ( \mathbf { 1 7 . 2 2 } )}$ \\
Writing & Frequent (a) & $\mathbf{5 . 8 8 ( 2 . 7 0 ) ^ { \mathbf { b } , \mathbf { c } }}$ & $9.22(2.17)$ & $10.18(6.87)$ & $13.83(5.75)$ & $70.58(17.95)$ \\
activity level & Occasional (b) & $\mathbf{4 . 1 7 ( 2 . 7 7 ) ^ { \mathbf { a } }}$ & $8.64(1.71)$ & $8.74(6.55)$ & $14.12(4.77)$ & $68.44(19.98)$ \\
& Rare (c) & $\mathbf{3 . 9 7 ( 2 . 4 5 ) ^ { \mathbf { a } }}$ & $8.51(1.78)$ & $7.63(4.41)$ & $14.27(3.42)$ & $67.43(15.96)$ \\
\hline
\end{tabular}


Table 6. ANCOVA results for the effect of gender with mean velocity as covariate and effect of writing activity level with mean velocity as covariate (values in bold $p<0.05$ )

\begin{tabular}{|c|c|c|c|c|c|}
\hline & & \multicolumn{2}{|c|}{$\begin{array}{l}\text { ANCOVA on Gender with mean } \\
\text { velocity as covariate }\end{array}$} & \multicolumn{2}{|c|}{$\begin{array}{l}\text { ANCOVA on Level of writing } \\
\text { activity with mean velocity as }\end{array}$} \\
\hline & & $\begin{array}{l}\text { Mean velocity } \\
(\mathrm{mm} / \mathrm{s})\end{array}$ & Gender & $\begin{array}{l}\text { Mean velocity } \\
(\mathrm{mm} / \mathrm{s})\end{array}$ & $\begin{array}{c}\text { Level of } \\
\text { writing activity }\end{array}$ \\
\hline Variable & dofs & 1 & 1 & 1 & 2 \\
\hline \multirow[t]{2}{*}{ Ave_Err\%_V (\%) } & $\mathrm{F}$ & 1.835 & 0.626 & 0.533 & 0.471 \\
\hline & $\mathrm{p}$ & 0.179 & 0.431 & 0.467 & 0.626 \\
\hline \multirow{2}{*}{ Ave_Err_V $(\mathrm{mm} / \mathrm{s})$} & $\mathrm{F}$ & 10.104 & 0.727 & 4.114 & 1.738 \\
\hline & $\mathrm{p}$ & 0.002 & 0.396 & 0.045 & 0.181 \\
\hline \multirow[t]{2}{*}{ Max_Err\%_V (\%) } & $\mathrm{F}$ & 0.003 & 0.020 & 0.050 & 0.103 \\
\hline & $\mathrm{p}$ & 0.955 & 0.888 & 0.823 & 0.902 \\
\hline \multirow[t]{2}{*}{ Max_Err_V $(\mathrm{mm} / \mathrm{s})$} & $\mathrm{F}$ & 4.378 & 1.210 & 2.313 & 0.125 \\
\hline & $\mathrm{p}$ & 0.039 & 0.274 & 0.132 & 0.883 \\
\hline \multirow{2}{*}{ Ave_Err\% (\%) } & $\mathrm{F}$ & 0.146 & 0.408 & 0.559 & 2.379 \\
\hline & $\mathrm{p}$ & 0.703 & 0.525 & 0.456 & 0.098 \\
\hline \multirow{2}{*}{ Ave_Err (mm) } & $\mathrm{F}$ & 2.567 & 1.522 & & \\
\hline & $\mathrm{p}$ & 0.112 & 0.220 & & \\
\hline \multirow[t]{2}{*}{ Max_Err\% (\%) } & $\mathrm{F}$ & 0.805 & 2.195 & 1.837 & 3.325 \\
\hline & $\mathrm{p}$ & 0.372 & 0.142 & 0.179 & 0.040 \\
\hline \multirow[t]{2}{*}{ Max_Err (mm) } & $\mathrm{F}$ & 2.644 & 1.375 & & \\
\hline & $\mathrm{p}$ & 0.107 & 0.244 & & \\
\hline \multirow{2}{*}{ Ave_Cur_Err\% $\%(\%)$} & $\mathrm{F}$ & 0.003 & 4.129 & 0.491 & 0.253 \\
\hline & $\mathrm{p}$ & 0.959 & 0.045 & 0.485 & 0.777 \\
\hline \multirow[t]{2}{*}{ Ave_Cur_Err (mm) } & $\mathrm{F}$ & 6.268 & 1.848 & 6.161 & 3.896 \\
\hline & $\mathrm{p}$ & 0.014 & 0.177 & 0.015 & 0.024 \\
\hline \multirow[t]{2}{*}{ Max_Cur_Err\% (\%) } & $\mathrm{F}$ & 2.070 & 0.539 & 2.698 & 2.358 \\
\hline & $\mathrm{p}$ & 0.153 & 0.465 & 0.104 & 0.100 \\
\hline \multirow{2}{*}{ Max_Cur_Err (mm) } & $\mathrm{F}$ & 6.094 & 1.508 & & \\
\hline & $\mathrm{p}$ & 0.015 & 0.222 & & \\
\hline \multirow[t]{2}{*}{ SNR (db) } & $\mathrm{F}$ & 0.106 & 4.247 & 0.112 & 0.079 \\
\hline & $\mathrm{p}$ & 0.746 & 0.042 & 0.738 & 0.924 \\
\hline
\end{tabular}


Table 7. Kruskal-Wallis results for the effect of writing activity level

\begin{tabular}{ccc}
\hline Kruskal-Wallis & $\mathrm{H}(2, \mathrm{~N}=99)$ & $\mathrm{p}$ \\
\hline Ave_Err $(\mathrm{mm})$ & 1.94 & 0.38 \\
Max_Err $(\mathrm{mm})$ & 2.39 & 0.30 \\
Max_Cur_Err & 1.29 & 0.52 \\
\hline
\end{tabular}


Figures Captions

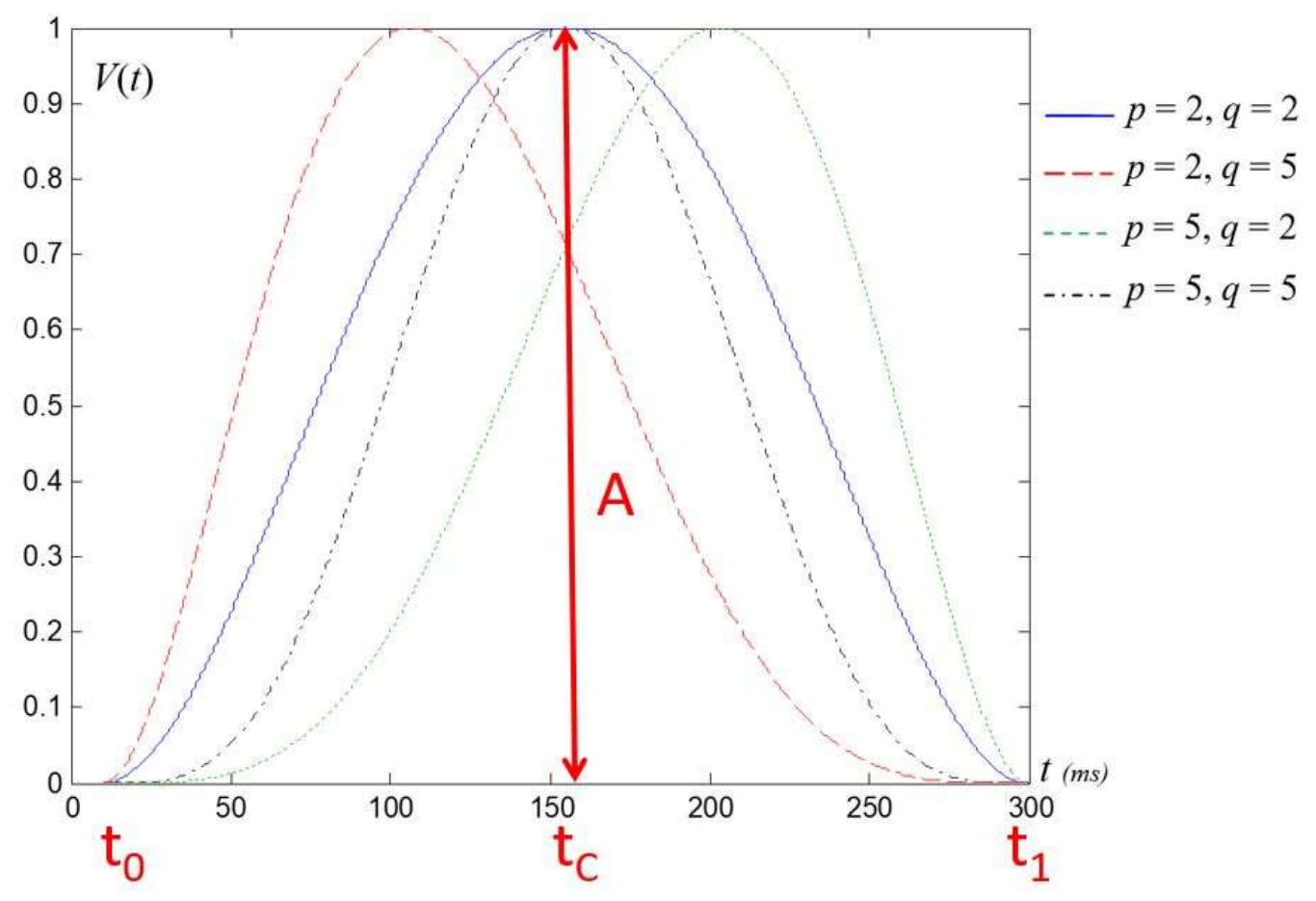

Fig. 1. Shape of a Beta impulse according to $\mathrm{p}$ and $\mathrm{q}$.

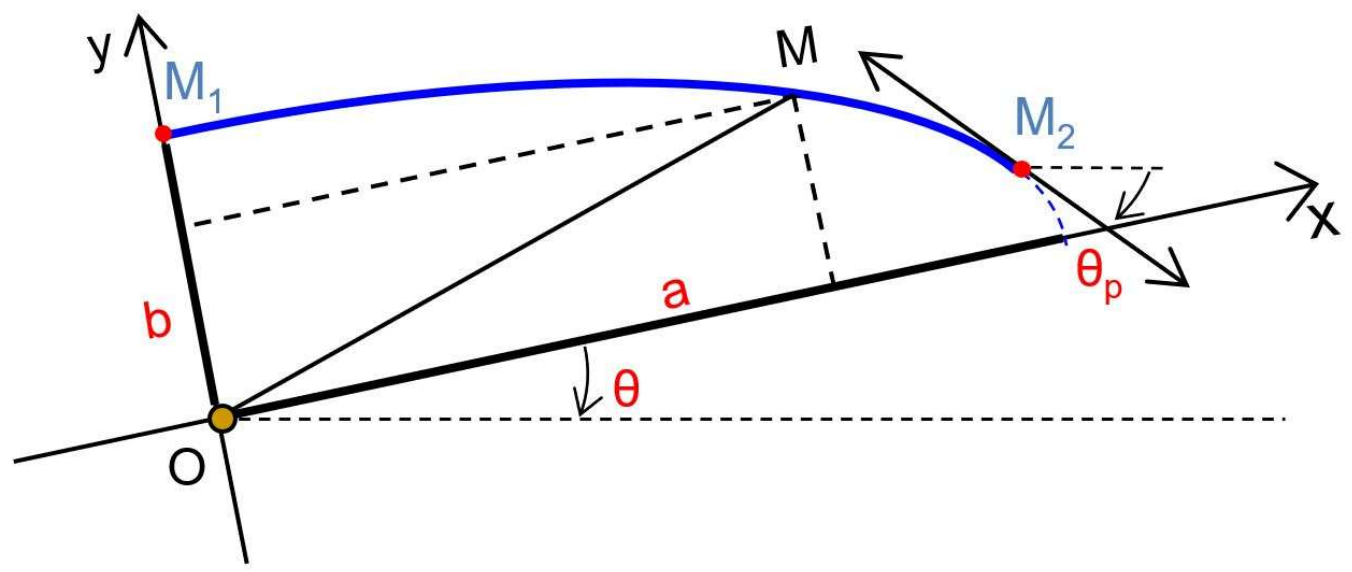

Fig. 2. Elliptic shape parameters generated by Beta-elliptic model. 


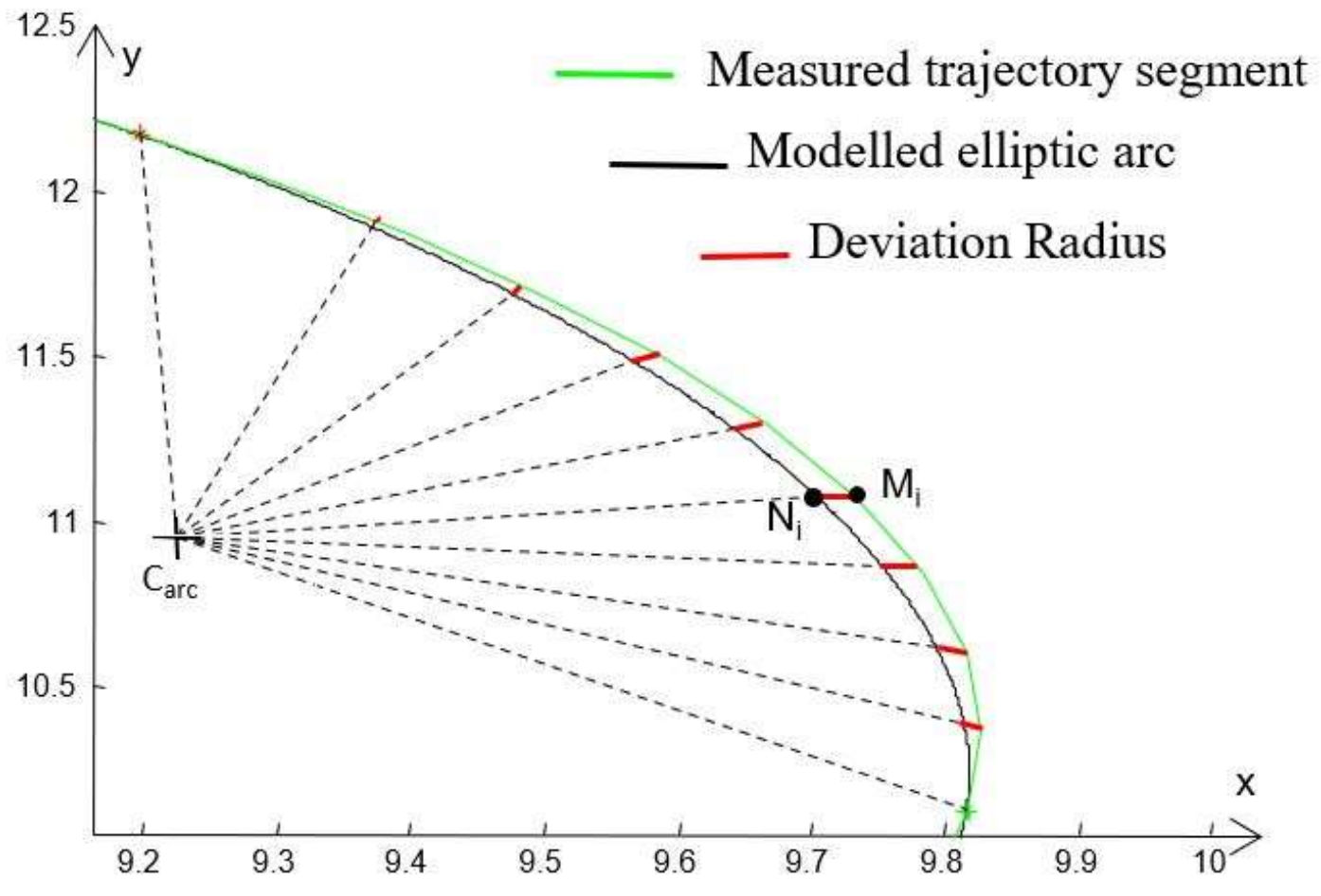

Fig. 3. Measurement of the deviation of an elliptic arc model with respect to the original trajectory segment. 

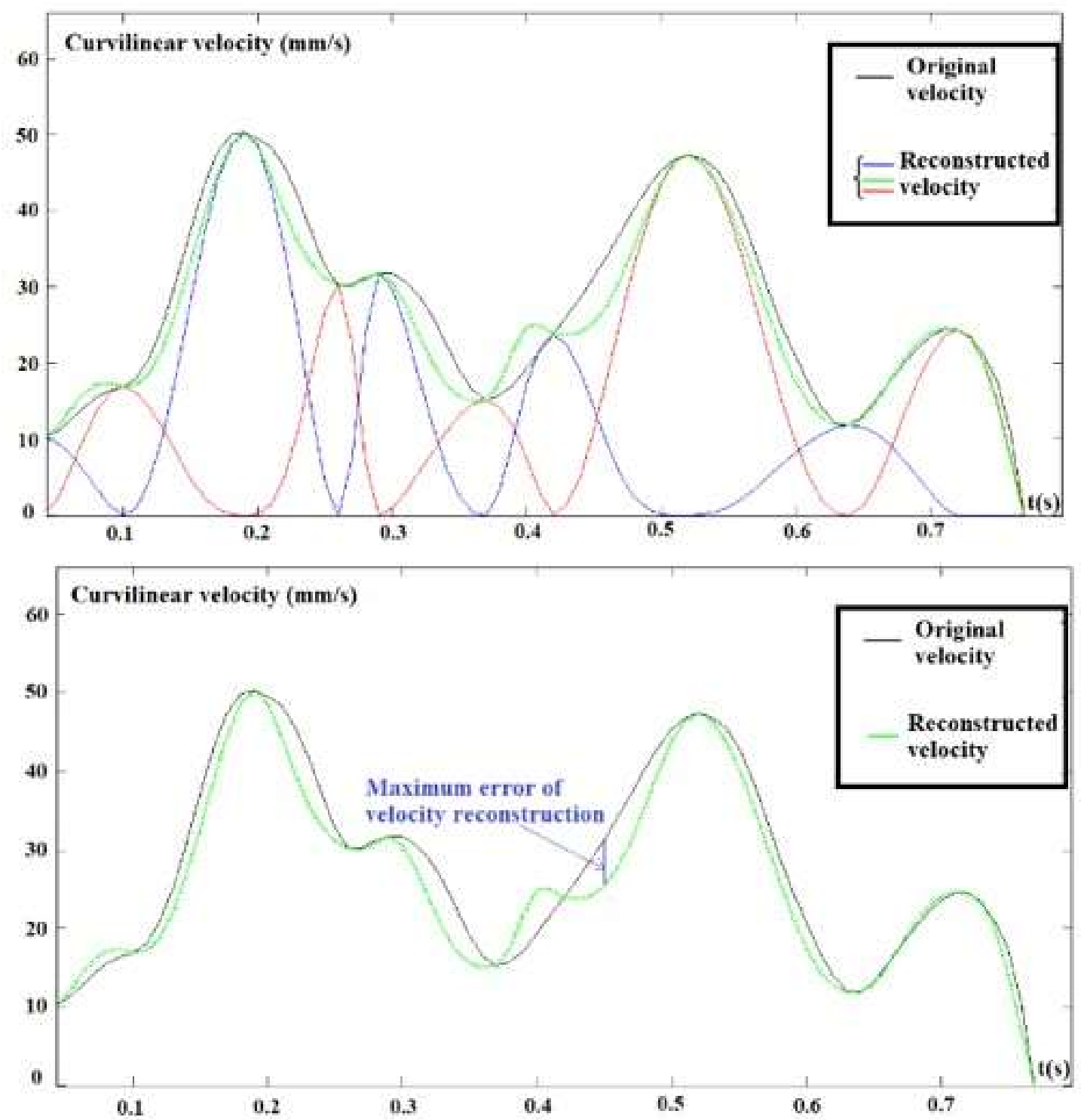

Fig. 4. Depiction of the maximum velocity error reconstruction. 


\section{Distribution of participants with age and gender}

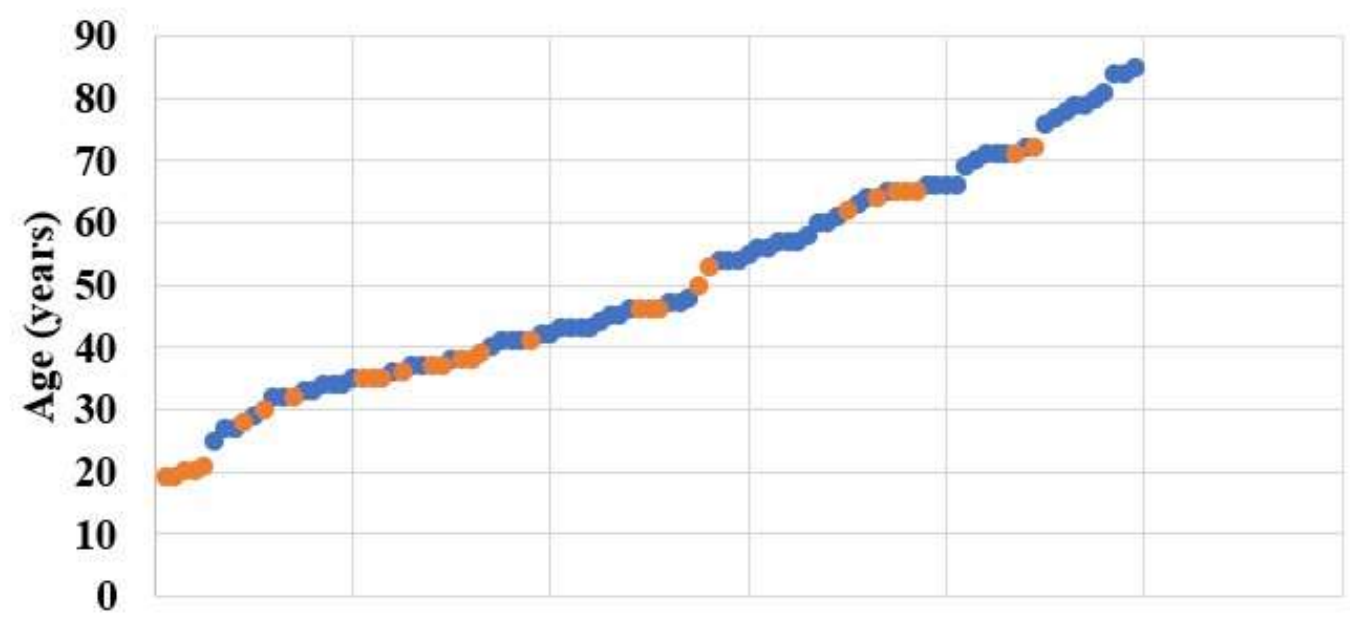

\section{Participant}

- Men - Women

Fig. 5. Distribution of participants according to age and gender, each dot represents one participant.

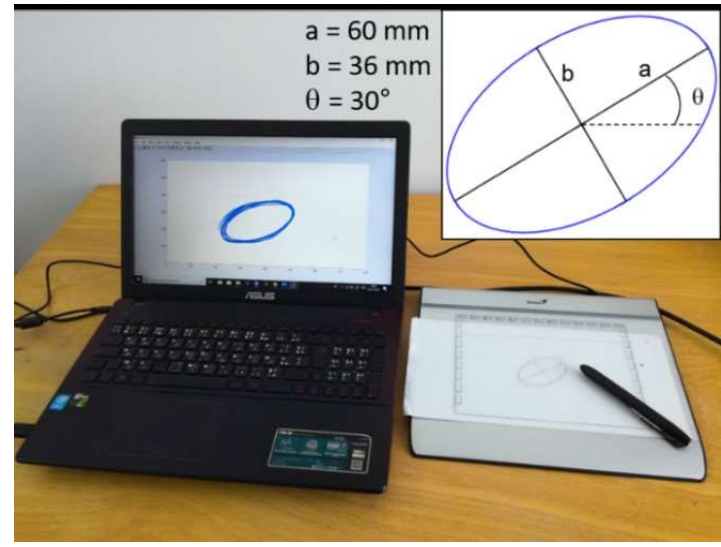

Fig. 6. Experimental setup with ellipse characteristics in the top right corner 

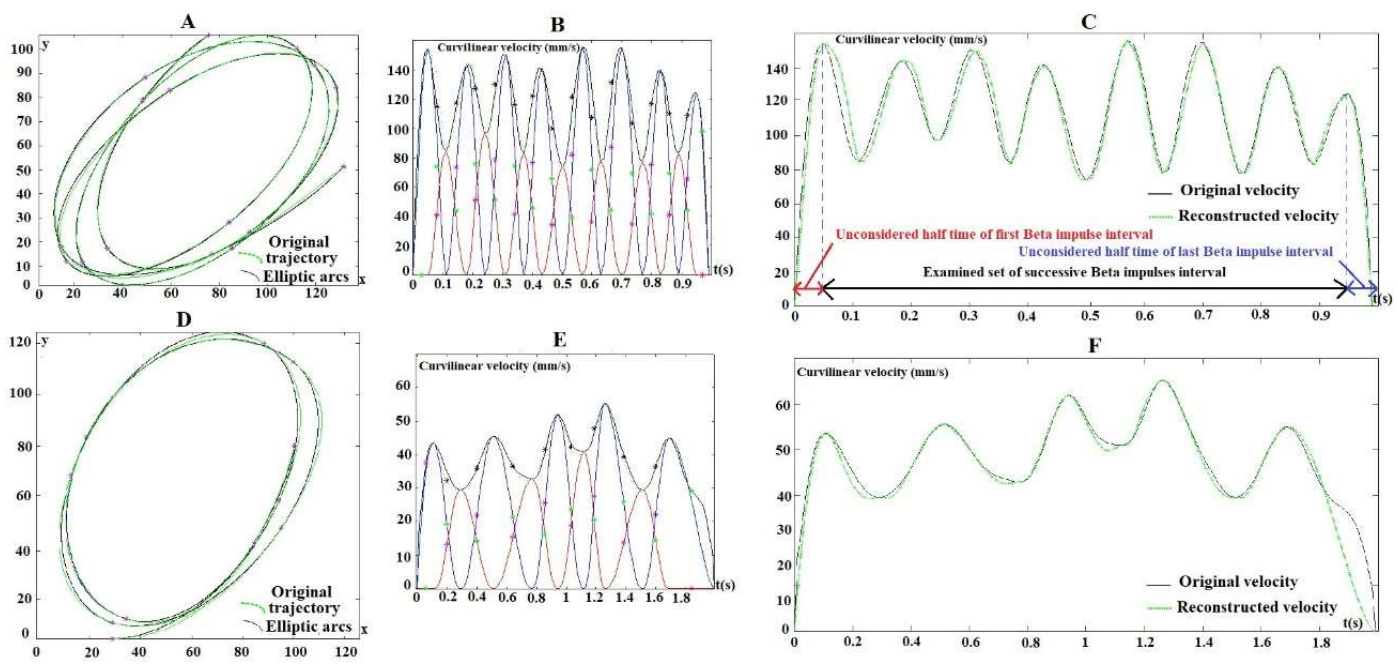

Fig. 7. Beta-elliptic modeling on two short trajectory samples from a subject aged 20 years (A, B and C) and 85 years (D, E and F). The left panel represents the elliptic arc fitting, the middle panel details the velocity profile decomposition with Beta functions and the right panel represents the fitted velocity profile

\section{Average error of geometric trajectory profile reconstruction vs. age and gender}

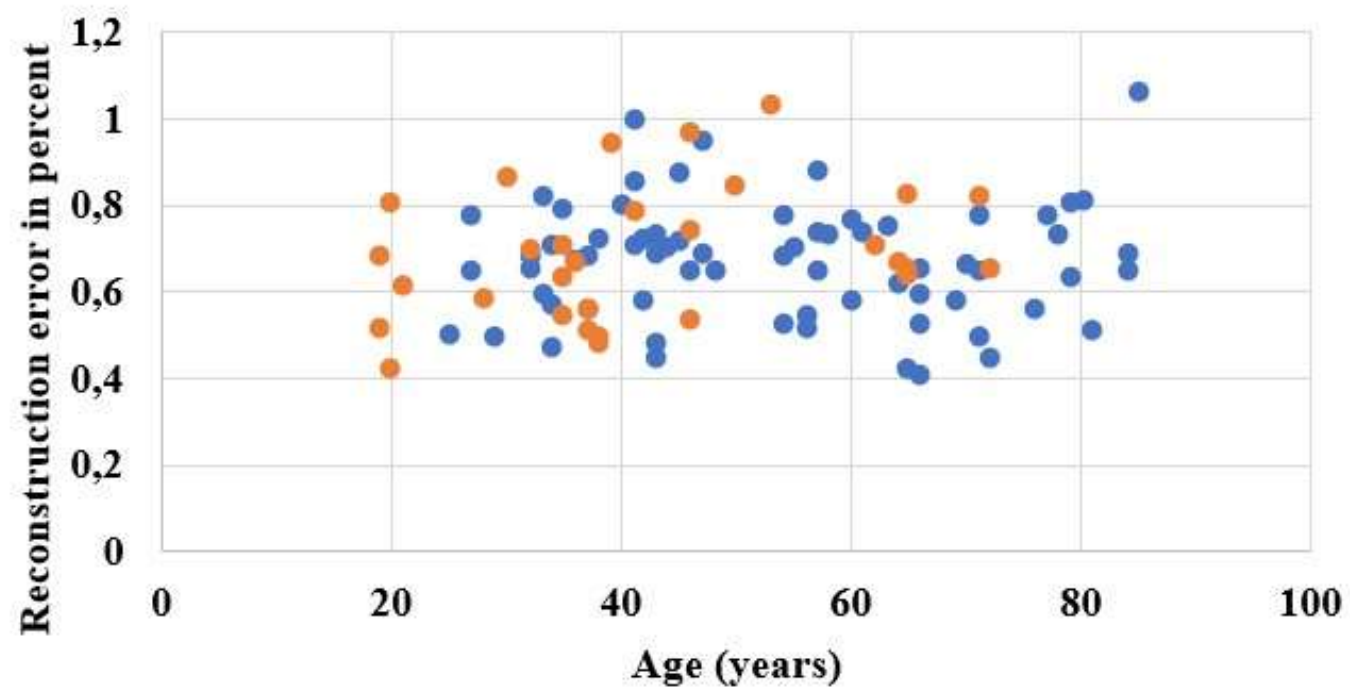

- Men - Women

Fig. 8. Average relative geometric error according to age and gender 
Average error of curvilinear velocity profile reconstruction vs. age and gender

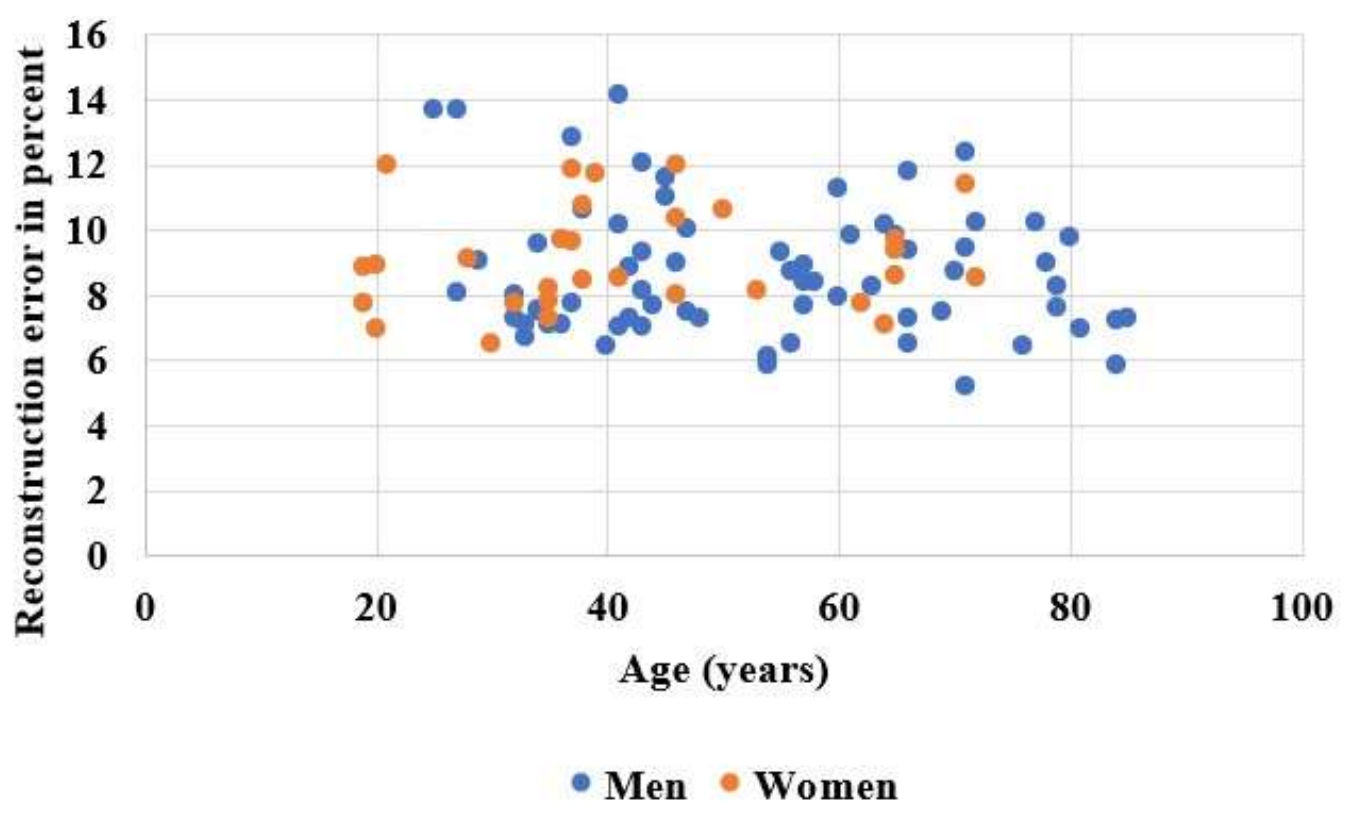

Fig. 9. Average relative velocity error according to age and gender

Average error of geometric trajectory profile reconstruction vs. age and degree of familiarity with writing

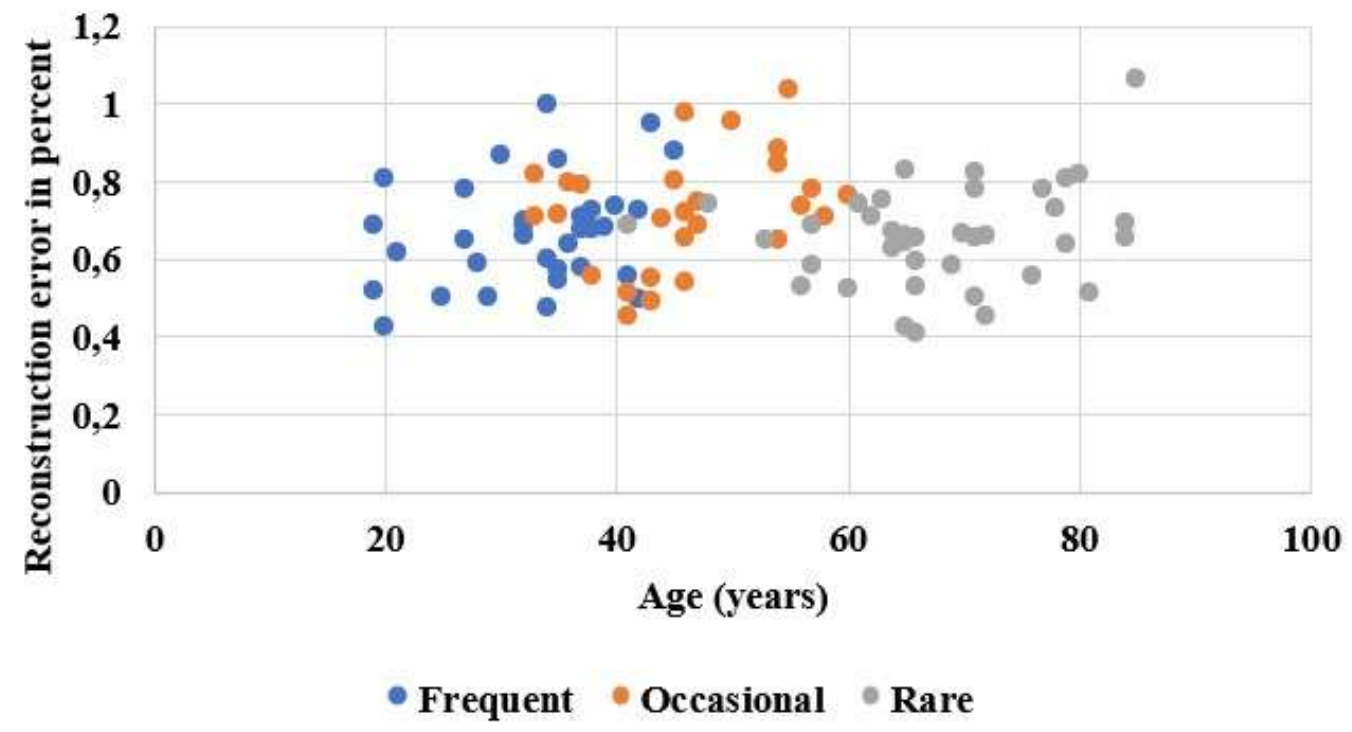

Fig. 10. Average relative geometric error according to age and writing activity level 
Average error of curvilinear velocity profile reconstruction vs. age and degree of familiarity with writing

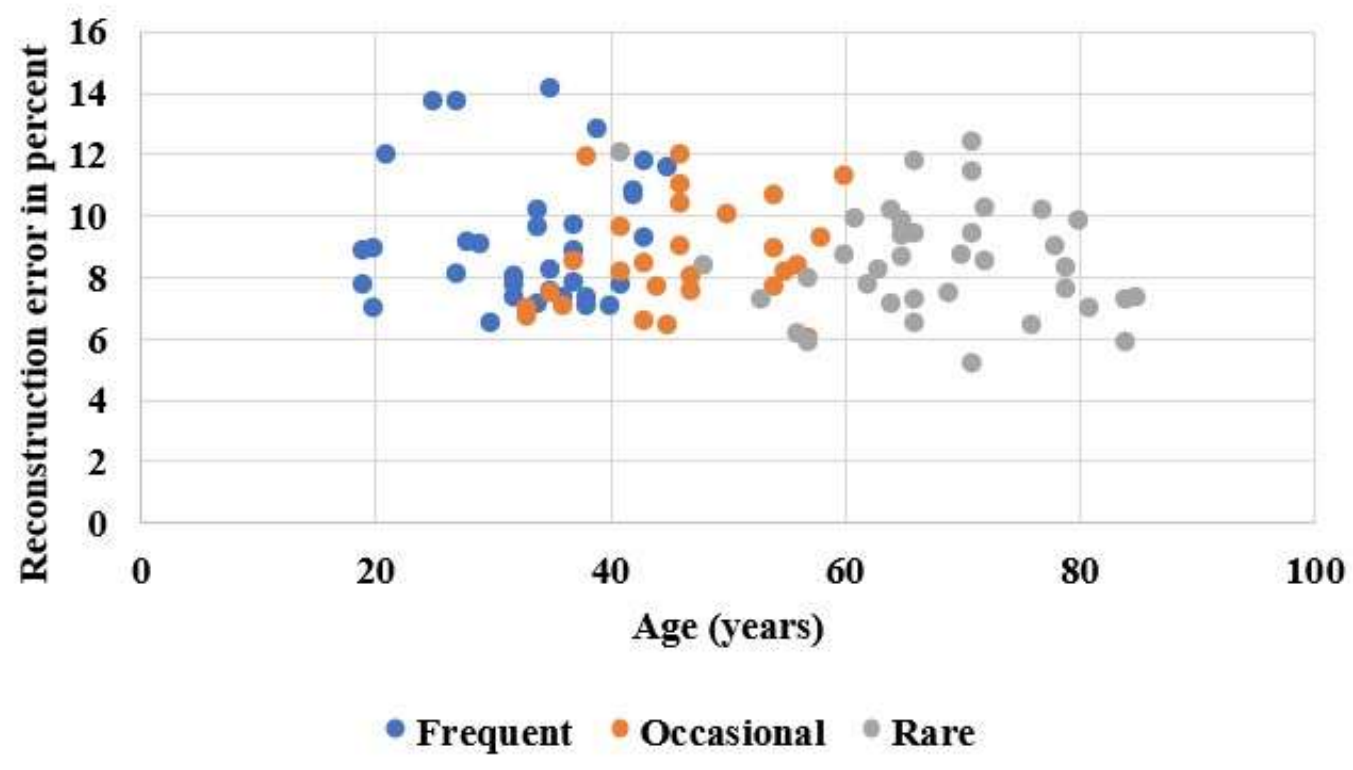

Fig. 11. Average relative velocity error according to age and writing activity level 